\title{
Identification of second layer adsorbates: water and chloroethane on $\mathrm{Pt}(111)$
}

\author{
Sam K. Jo, J. Kiss *, J.A. Polanco ** and J.M. White \\ Center for Materials Chemistry and Department of Chemistry, The University of Texas at Austin, Austin, TX 78712-1167, USA
}

Received 16 October 1990; accepted for publication 5 February 1991

\begin{abstract}
We show temperature-programmed desorption (TPD) evidence of (1) resolvable adsorbate structure within water bilayers and (2) a second layer peak for $\mathrm{C}_{2} \mathrm{H}_{5} \mathrm{Cl}$ on $\mathrm{Pt}(111)$ that is distinguishable both from the first layer and from thicker multilayers. The sticking probability of water was independent of the surface temperature between 55 and $150 \mathrm{~K}$, but was significantly (30\%) smaller at low coverage than on a multilayer-covered surface. The TPD of $\mathrm{C}_{2} \mathrm{H}_{5} \mathrm{Cl}$ is quite sensitive to the nature of preadsorbed water.
\end{abstract}

\section{Introduction}

Water-surface interactions, of great scientific and practical importance, have attracted scientists from various disciplines, including meteorology, geology, electrochemistry, catalysis, surface processing [1], and corrosion chemistry. This fundamental and intriguing field continues to draw attention. Thiel and Madey [2] recently have reviewed the subject comprehensively, and we refer interested readers to this elegant monograph.

Well-defined and chemically-modified surfaces of metals, oxides and semiconductors, together with surface-sensitive UHV spectroscopies, have been widely employed in water-surface studies [2]. Frequently-used techniques include temperature-programmed desorption spectroscopy (TPD or TDS), ultraviolet photoemission spectroscopy (UPS), X-ray photoelectron spectroscopy (XPS), high-resolution electron energy-loss spectroscopy (HREELS), low-energy electron diffraction (LEED), electron-stimulated desorption ion-angu-

* Visiting scholar from Reaction Kinetics Research Group of the Hungarian Academy of Sciences, University of Szeged, P.O. Box 105, H-6701, Szeged, Hungary.

** Visiting summer student from Department of Physics, The University of Texas at El Paso, El Paso, TX 79968, USA. lar distribution (ESDIAD), and surface workfunction change $(\Delta \phi)$ measurements.

Platinum surfaces have been of special interest in heterogeneous catalysis and electrochemistry. For example, detailed knowledge of the orientations of water molecules at a metal-electrolyte interface is essential to the understanding of many electrocatalytic reactions. Since the first detailed thermal desorption study of water on the lowestenergy face (111) of platinum by Fisher and Gland [3] a decade ago, many publications have appeared [4-6]. Briefly, the literature on the waterPt(111) system [2,3] concludes that: (1) water molecularly adsorbs and desorbs with two peaks: 160-165 K (physisorhed) and 175-180 K (weakly chemisorbed); (2) water bonds through the oxygen atom, resulting in charge transfer to the surface (negative work function changes); (3) water adsorbs with a near-unity sticking coefficient, regardless of surface temperature $(<150 \mathrm{~K})$ and water-coverage, and desorbs with fractional-order (chemisorbed) and zero-order (physisorbed) kinetics; (4) the first layer consists of a two-tiered structure, often called "bilayer", a feature attributed to the unique hydrogen bonds between water molecules; and (5) hydrogen-bonded clusters (or islands) are present even at very low coverages.

The bilayer is a two-tiered three-dimensional 


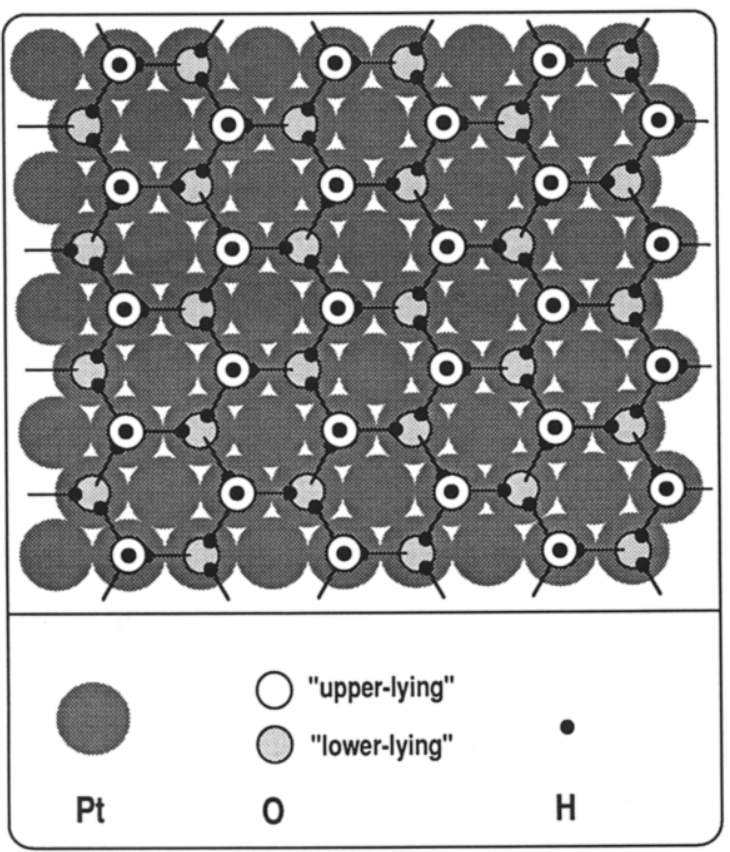

Scheme 1. The surface structure of water on $\operatorname{Pt}(111)$.

structure in which the water molecules in the lower half are directly bonded to the surface, and those in the upper half (raised from the lower half by about $1 \AA$ ) are held by two or three hydrogen bonds to the lower molecules, resulting in a hexagonal honeycomb structure $[2,7,8]$. Scheme 1 shows a model of this structure, with long-range order, which has been developed on the basis of many spectroscopic observations and calculations $[2,7,8]$. Two water desorption peaks, separated by about $30 \mathrm{~K}$ and attributed to this bilayer structure, have been observed on $\mathrm{Ni}(110)[9,10]$ and on $\mathrm{Ru}(001)$ [2,7], but not on $\operatorname{Pt}(111)[3,11,12]$.

The work described here was undertaken as part of a broader investigation of photon- and electron-induced surface chemical reactions. In particular, having examined the photon-driven chemistry of water and alkyl halides, individually [18], we were interested in extensions to coadsorbed layers involving water because of the possible insight the results could provide into electrochemical and environmental problems. We report TPD evidence for the known water bilayer structure, and a sticking coefficient significantly lower than unity for water on $\mathrm{Pt}(111)$. We also show
TPD distinction of the second layer $\mathrm{C}_{2} \mathrm{H}_{5} \mathrm{Cl}$ from the first and third or higher layers on $\operatorname{Pt}(111)$, and probe the water structure using the site-sensitive desorption characteristics of $\mathrm{C}_{2} \mathrm{H}_{5} \mathrm{Cl}$. We also achieve excellent TPD resolution $(\leq 4 \mathrm{~K})$ and reproducibility by using a carefully designed gas dosing-thermal desorption system detailed in the following section.

\section{Experimental}

We used a UHV chamber equipped with XPS (Kratos Series 800), UPS (VG), quadrupole mass spectroscopy (QMS; UTI 100C) for TPD and residual gas analysis (RGA), an ion gun (Kratos), a closed-cycle He cryostat for the sample cooling, and a pin-hole gas doser. The chamber was pumped by a $360 \ell / \mathrm{s}$ turbomolecular pump with a background pressure $2.5 \times 10^{-10}$ torr. The X-ray source, He-discharge light source, sputtering gun, and the rotational stage of the sample manipulator (cryostat) were all differentially pumped by extra pairs of rotary and turbo pumps.

A Pt(111) single crystal disc $(0.8 \mathrm{~cm}$ diameter, $0.1 \mathrm{~cm}$ thick) was mounted on a pair of Ta wires, which had direct thermal contact with a pair of oxygen-free high conductivity (OHFC) Cu blocks through a pair of $\mathrm{Ta}$ rods $\left(0.125^{\prime \prime}\right.$ diameter $)$. The $\mathrm{Cu}$ blocks were electrically insulated from, but had good thermal contact with the second stage cooling station $(\sim 40 \mathrm{~K})$ of the He cryostat, through a pair of sapphire sheets $\left(0.02^{\prime \prime} \times 0.5^{\prime \prime} \times\right.$ $\left.1.5^{\prime \prime}\right)$. In this way, the crystal could be cooled to $50 \mathrm{~K}$ (within $4 \mathrm{~min}$ after flash-heating to $500 \mathrm{~K}$ ) and heated with a linear ramp $(0.1$ to $50 \mathrm{~K} / \mathrm{s})$ to $1500 \mathrm{~K}$. An $\sim 6 \mathrm{~K} / \mathrm{s}$ ramp was used for the TPD spectra presented here. The crystal temperature was monitored using a chromel-alumel thermocouple spot-welded to the back of the crystal. Thermal desorption signals were collected with an IBM personal computer using software that allows monitoring up to 10 different masses simultaneously. The $\operatorname{Pt}(111)$ surface was cleaned by a series of sputter-anneal-oxidation cycles, each consisting of $\mathrm{Ne}^{+}$ion sputtering at $800 \mathrm{~K}, 1400 \mathrm{~K}$ anneal, oxidation at $800 \mathrm{~K}$, and another $1400 \mathrm{~K}$ 
anneal. The surface cleanliness was confirmed by XPS and TPD.

Adsorbate molecules were dosed through a retractable pin-hole doser mounted on a linear motion device [13]. A pin-hole ( $2 \mu \mathrm{m}$ diameter $)$ disc (Ni-Co bimetal) of $0.25^{\prime \prime}$ diameter was positioned in the middle of the doser $\left(0.25^{\prime \prime}\right.$ diameter stainless steel tube) and vacuum-sealed by two $\mathrm{Cu}$ gaskets using a VCR joint. The distance between the pin-hole and doser tip was about $7 \mathrm{~cm}$. Exposures were controlled by keeping the reservoir pressure $(2.00 \pm 0.005$ Torr) constant and varying the dosing time. The crystal-to-doser distance was $2.00 \pm 0.005 \mathrm{~mm}$ during doses. With this distance, the ion gauge failed to detect pressure rises $\left(<10^{-11}\right.$ Torr) above the background level during the dosing of water and ethyl chloride. This doser geometry, which minimizes the exposure to surfaces other than the front crystal surface and provides a uniform molecular flux to the surface, assured an improved reproducibility of peak areas (within 3\%) and peak resolution ( $\leq 4 \mathrm{~K})$ in TPD spectra.

Careful attention to mounting of the the crystal onto the Ta wires improved its uniform heating, also an important factor for TPD resolution. There was no significant change $(<0.001 \mathrm{~K} / \mathrm{s})$ in the ramp rate between 100 and $200 \mathrm{~K}$. The density of the data points was about 1 point per $1 \mathrm{~K}$, another requirement for high resolution TPD.

The gases used for cleaning, $\mathrm{O}_{2}, \mathrm{H}_{2}$, were dosed through a separate tubular $\left(0.25^{\prime \prime}\right.$ diameter $)$ doser,
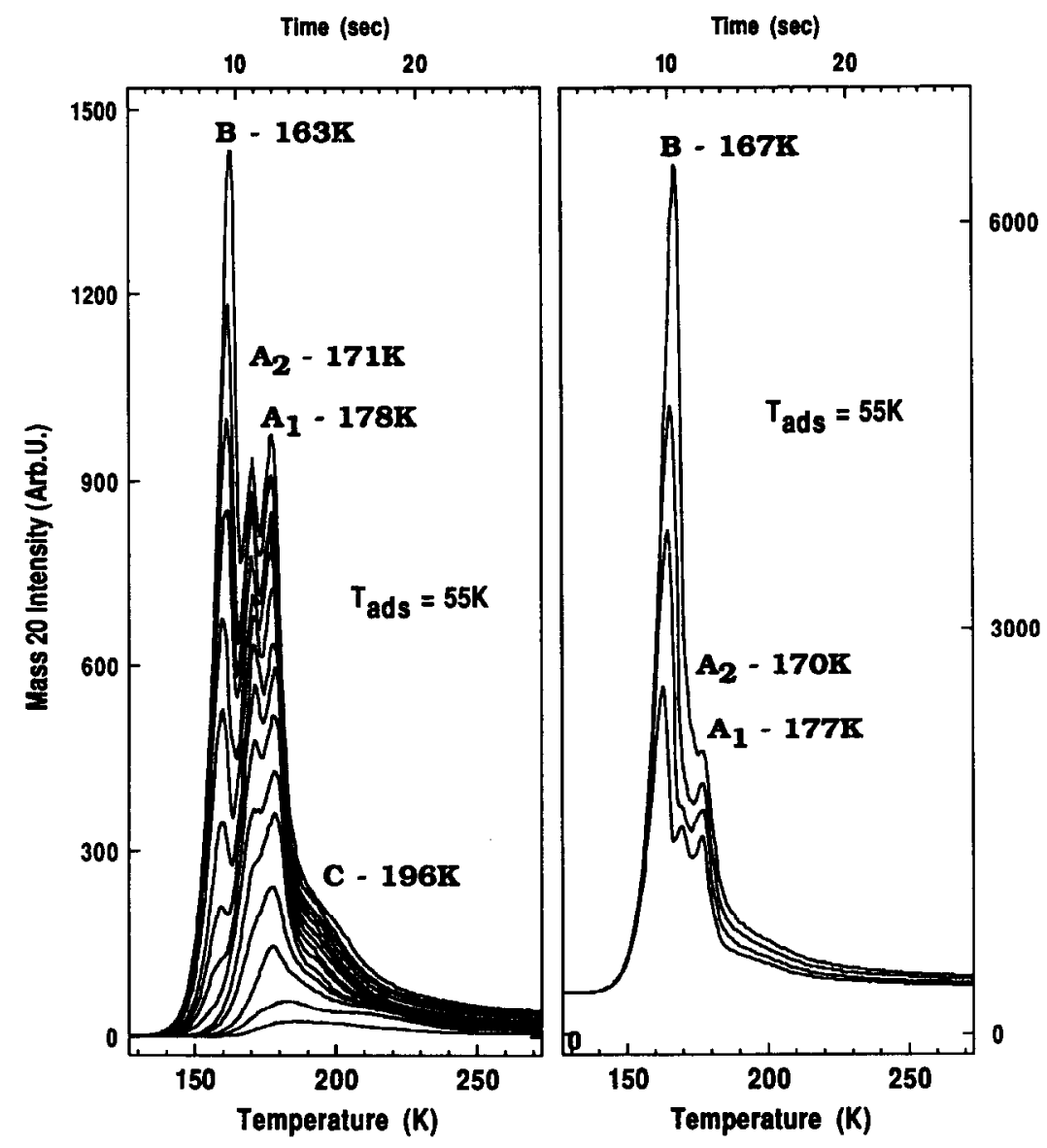

Fig. 1. TPD spectra of $\mathrm{D}_{2} \mathrm{O}$ dosed at $55 \mathrm{~K}$ on $\mathrm{Pt}(111)$. Exposure times (in seconds) are, from bottom to top, 20, 35, 50, 65, 80, 95, 110, $125,140,155,170,185,200,215$, and 230 (the left panel); 300, 400, 500, and 600 (the right panel). The top axes show the times elapsed from the start of the linear temperature $\operatorname{ramp}(6.306 \mathrm{~K} / \mathrm{s})$. 
controlled with a leak-valve and terminating $3 \mathrm{~cm}$ away from the crystal, was used. The crystal-toQMS distance was about $5 \mathrm{~cm}$. Rotating the sample manipulator toward the QMS allowed line-ofsight TPD. Deuterium oxide, $\mathrm{D}_{2} \mathrm{O}$ (Aldrich; 99.8 at\% D), was further purified with freeze-pumpthaw cycles before dosing. We also confirmed the absence of isotope effects [14] in TPD spectra by dosing $\mathrm{H}_{2} \mathrm{O}$ occasionally. Ethyl chloride, $\mathrm{C}_{2} \mathrm{H}_{5} \mathrm{Cl}$ (Lindc; 99.7\%), was used without further purification from a lecture bottle.

\section{Results}

\section{1. $\mathrm{D}_{2} \mathrm{O}$ on clean, oxygen- and deuterium- precovered Pt(111)}

Fig. 1 shows a series of TPD spectra of $\mathrm{D}_{2} \mathrm{O}$ dosed at $55 \mathrm{~K}$ on clean $\mathrm{Pt}(111)$ for low (left panel) and high (right panel) exposures. Also shown (top axes) are the times elapsed from the start of the temperature ramp, which gives a $6.305 \mathrm{~K} / \mathrm{s} \mathrm{ramp}$ rate. Even for very low exposures there are already desorption peaks at $196 \mathrm{~K}(\mathrm{C})$ and $178 \mathrm{~K}\left(\mathrm{~A}_{1}\right)$. With increasing exposure, third $\left(171 \mathrm{~K} ; \mathrm{A}_{2}\right)$ and fourth (160-167 K; B) peaks grow in. The 160-167 $\mathrm{K}$ peak (B), which shifts to higher temperatures with increasing exposure and does not saturate, indicates desorption from a physisorbed state, i.e., ice multilayers. The relative intensities of the high temperature $\mathrm{D}_{2} \mathrm{O}$ desorption $(\mathrm{C})$ vary with background $\mathrm{O}_{2}$ pressure (see figs. 1 and 2). This peak is, as previously, assigned to the surface reaction, $2 \mathrm{OD}$ (a) $\rightarrow \mathrm{D}_{2} \mathrm{O}$ (g) $+\mathrm{O}$ (a) [3], an assignment supported by the oxygen-precoverage results (fig. 3 ). There was no XPS or other TPD evidence for any dissociation of adsorbed water. 1 monolayer (ML) was defined as the coverage of the highest exposure ( $\sim 110 \mathrm{~s}$ dose) which gave no $163 \mathrm{~K}$ desorption. The saturation monolayer coverage of water (bilayer) on $\mathrm{Pt}(111)$ corresponds to 0.67 $(2 / 3) \mathrm{D}_{2} \mathrm{O}$ molecule per $\mathrm{Pt}$ atom [2]. In comparable work, Fisher and Gland [3] reported a detailed series of TPD spectra for $\mathrm{H}_{2} \mathrm{O}$ on $\mathrm{Pt}(111)$. They observed three desorption peaks, which match regions $A, B$ and $C$, but did not resolve $A_{1}$ and $A_{2}$.

The split desorption $\left(A_{1}\right.$ and $\left.A_{2}\right)$ of the first

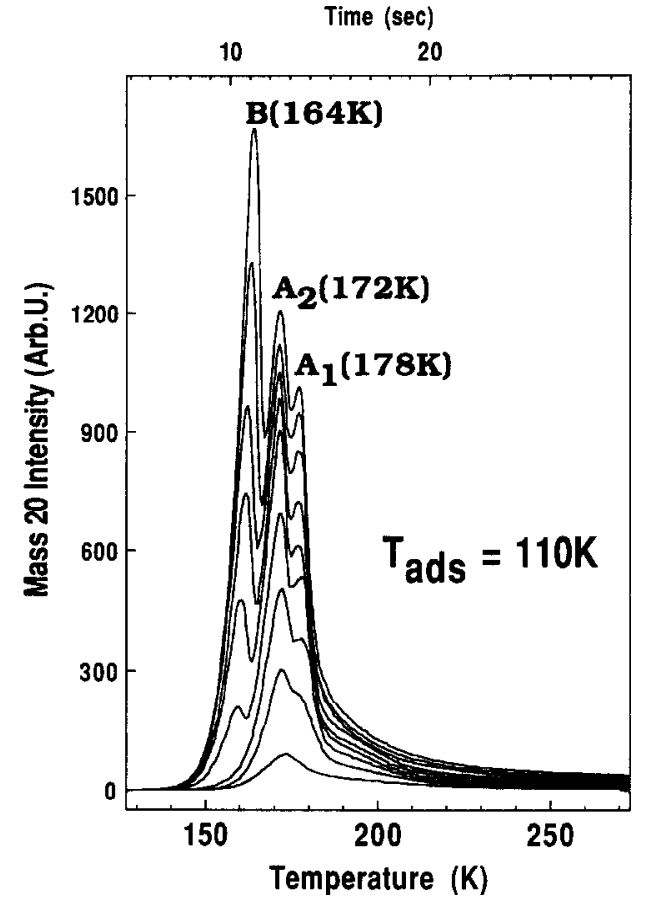

Fig. 2. TPD spectra of $\mathrm{D}_{2} \mathrm{O}$ dosed at $110 \mathrm{~K}$ on $\mathrm{Pt}(111)$. Exposure times (in seconds) are, from bottom to top, 27, 55, $83,110,137,165,193,220$, and 247.

monolayer, which has been clearly identified previously on $\mathrm{Ni}(110)[9,10]$ and $\mathrm{Ru}(001)[2,7]$, but not $\mathrm{Pt}(111)[3,11,12]$, is one of the most interesting findings in this study. The peak $\left(\mathrm{A}_{2}\right)$, with other supporting evidence in this work, is attributed to desorption from surface regions where the bilayer is well-established (see scheme 1).

Fig. 2 shows analogous TPD spectra, but dosed at $110 \mathrm{~K}$. The desorption features are like those of $55 \mathrm{~K}$ doses (see the left panel of fig. 1), except the $172 \mathrm{~K}\left(\mathrm{~A}_{2}\right)$ peak grows in earlier and retains relatively higher intensity compared with the $55 \mathrm{~K}$ doses. Adsorption at 130 and $150 \mathrm{~K}$ gave TPD spectra which were qualitatively the same except for slightly higher relative intensity at $172 \mathrm{~K}$. These differences in the relative populations of the two $\left(A_{1}\right.$ and $A_{2}$ ) states will be discussed further, in relation to the bilayer structure, in the following section.

Because water is known to behave differently in the presence of oxygen, the behavior of $\mathrm{D}_{2} \mathrm{O}$ was examined on molecular and atomic oxygen-pre- 
covered $\mathrm{Pt}(111)$, the latter prepared by annealing an $\mathrm{O}_{2}$-predosed surface to $300 \mathrm{~K}$. Since $\mathrm{O}_{2}$ was dosed using a directed tubular doser connected to a leak valve, the actual exposure is unknown because of the unknown directional enhancement. However, the complete suppression of the 172 and $178 \mathrm{~K} \mathrm{D}_{2} \mathrm{O}$ peaks (see below) suggests that the oxygen exposure is near saturation.

As shown in fig. 3 , on $\mathrm{O}_{2}$-precovered surfaces, the $\Lambda_{2}$ and $\Lambda_{1}$ peaks are completely suppressed, the multilayer peak remains, and a new peak appears at $203 \mathrm{~K}$. When the surface is precovered with atomic oxygen, the situation is only slightly different; a peak at $167 \mathrm{~K}$ grows in before the 163 $\mathrm{K}$ peak, and saturates at about the same peak height as the $204 \mathrm{~K}$ peak. Fisher and Gland [3] have shown strong evidence that the peaks near
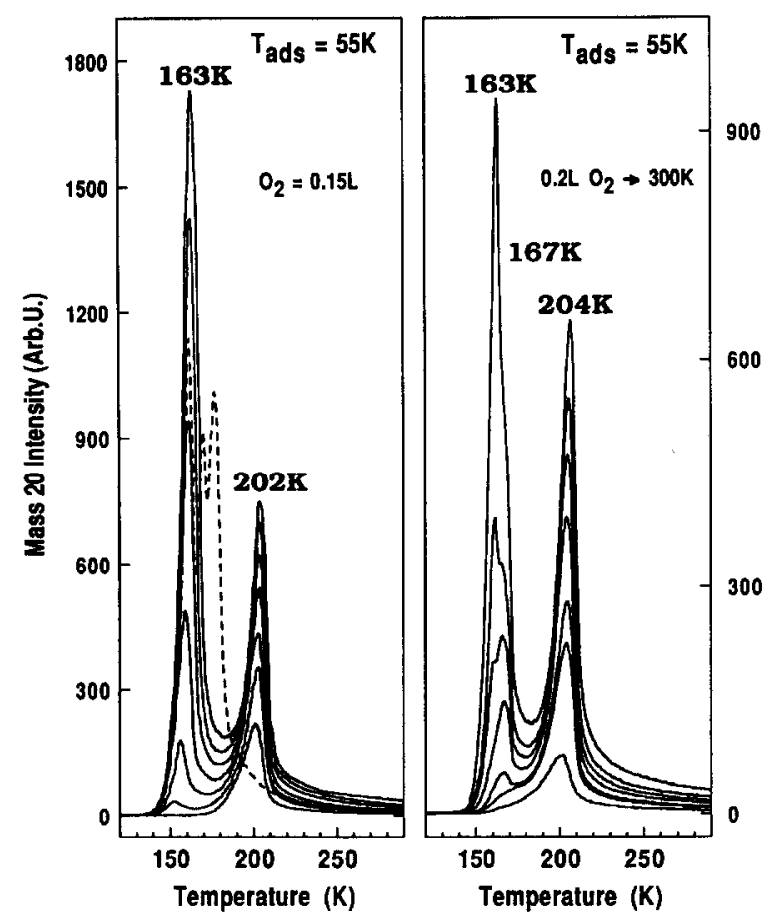

Fig. 3. TPD spectra of $\mathrm{D}_{2} \mathrm{O}$ adsorbed at $60 \mathrm{~K}$ on (a) $\mathrm{O}_{2}$-precovered $\left(0.15 \mathrm{~L}\right.$ exposure) and (b) O-precovered $\left(0.2 \mathrm{~L}_{2}\right.$ exposure followed by $300 \mathrm{~K}$ anneal) $\mathrm{Pt}(111) . \mathrm{D}_{2} \mathrm{O}$ exposure times (in seconds) are, in the order of increasing intensity, 55, $83,110,165,220,280$ and 330 (the left panel); 27, 55, 66, 110, 138,165 and 220 (the right panel). Also shown is $2 \mathrm{ML}(220 \mathrm{~s}$ dose) $\mathrm{D}_{2} \mathrm{O}$ TPD (dashed curve) on the oxygen-free surface for comparison.
$200 \mathrm{~K}$ (figs. 1 and 3, respectively) originate from $\mathrm{OH}$ recombination.

TPD of $\mathrm{D}_{2} \mathrm{O}$ adsorbed at $60 \mathrm{~K}$ on deuteriumprecovered $\operatorname{Pt}(111)$ is shown in fig. 4. The left panel shows $\mathrm{D}_{2} \mathrm{O}$ TPD spectra of a fixed dose $(137 \mathrm{~s} \cong 1.25 \mathrm{ME})$ of $\mathrm{D}_{2} \mathrm{O}$ for a series of $\mathrm{D}$-precoverages. With increasing D-coverage $(0-0.24 \mathrm{~L}$ range), the $171 \mathrm{~K}$ peak is quickly suppressed, while the width, desorption temperature and the intensity of the $177 \mathrm{~K}$ pcak increasc slightly. A further increase ( $>0.24 \mathrm{~L}$ ) in D-coverage gradually shifts the $177 \mathrm{~K}$ peak downward, reaching 170 $K$ near D-saturation. This result precludes the possibility that background hydrogen pre-adsorption causes the split desorption $\left(A_{1}\right.$ and $\left.A_{2}\right)$ of the first monolayer of water. Also shown (the inset) is the $\mathrm{D}_{2} \mathrm{O}$ uptake (integrated TPD area for $137 \mathrm{~s}$ dose) versus $D$-precoverage, which indicates that the sticking probability of water is lower (by $-20 \%$ ) on the D-covered surface than on clean $\operatorname{Pt}(111)$. The right panel shows a series of $\mathrm{D}_{2} \mathrm{O}$ TPD spectra on D-saturated Pt(111). Only two desorption peaks (155-163 $\mathrm{K}$ and 166-171 $\mathrm{K}$ ) were observed for all exposures; there is no hint of a peak at $178 \mathrm{~K}$ as in fig. 1 . Note that the $171 \mathrm{~K}$ peak also shifts from $166 \mathrm{~K}$ to higher temperatures with increasing exposure, suggesting a fractional-order desorption. The absence of a peak at $203 \mathrm{~K}$ is consistent with there being no $\mathrm{D}_{2} \mathrm{O}$ decomposition on the D-precovered surface.

Fig. 5 is a plot of $\mathrm{D}_{2} \mathrm{O}$ uptake (integrated TPD peak area) curves versus exposure time for various adsorption temperatures on clean and molecular $\mathrm{O}_{2}$-precovered surfaces. On the clean surface, two points can be made: (1) the adsorption temperature does not affect the uptake, i.e., the sticking coefficient is temperature-independent; and (2) two distinctly linear regions are obtained, implying that, in this study, unlike some others $[9,15-$ 17], the sticking coefficient is coverage-dependent. The slope of the $0-110 \mathrm{~s}$ range was $70 \%$ of that of the $>110 \mathrm{~s}$ range, indicating that the sticking coefficient on the clean surface is 0.7 or lower. This conclusion, based on desorption of molecular water, requires that there be no other channel, e.g. dissociation to form $\mathrm{O}$ and $\mathrm{H}$, through which adsorbed water can pass. As indicated earlier, there was no XPS evidence for accumulation of $O$ 

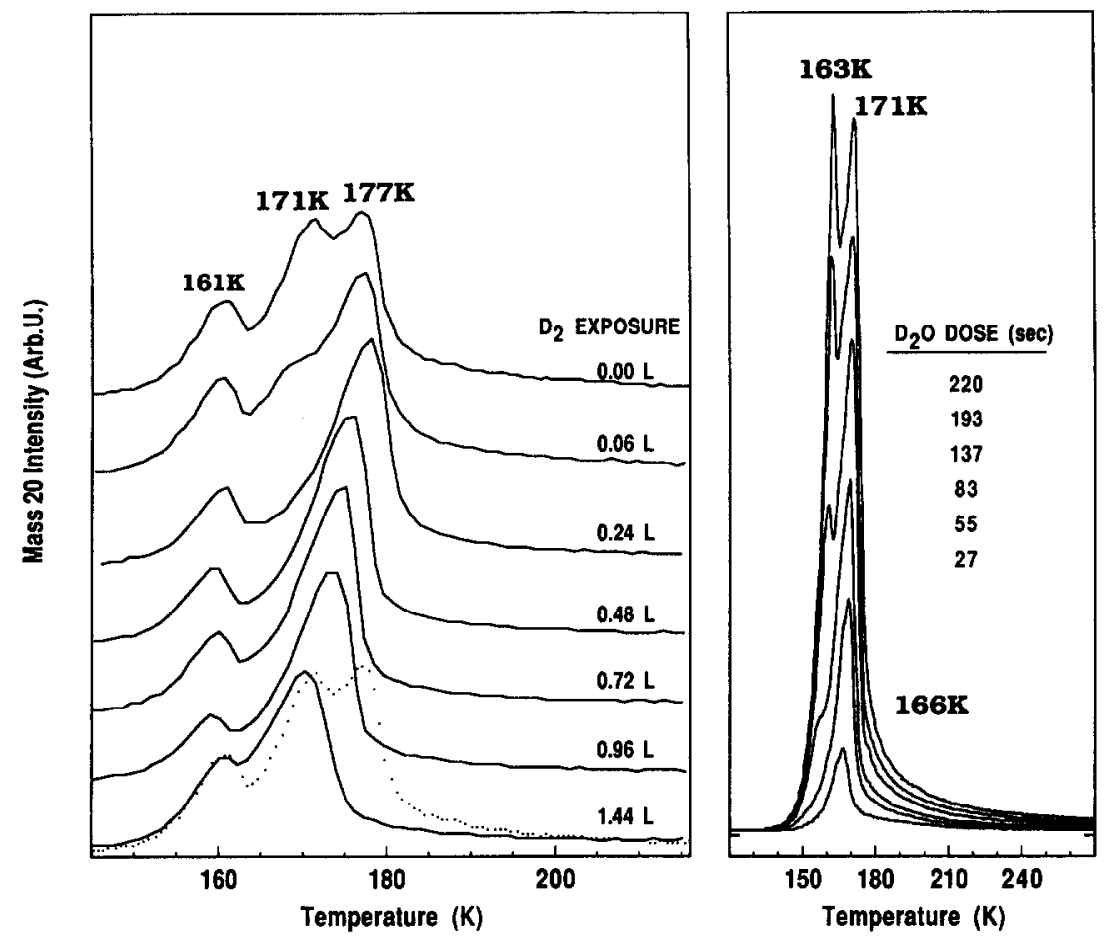

Fig. 4. $\mathrm{D}_{2} \mathrm{O}$ TPD spectra on deuterium-precovered $\mathrm{Pt}(111)$ for: (the left panel) a fixed $\mathrm{D}_{2} \mathrm{O}$ dose (137 $\left.\mathrm{s} \sim 1.25 \mathrm{ML}\right)$ with various $\mathrm{D}$-precoverages; (the right panel) various $\mathrm{D}_{2} \mathrm{O}$ doses with a fixed $(1.44 \mathrm{~L} \sim$ saturation) $\mathrm{D}$-precoverage. The dot curve is the top curve drawn on the same background level as that of the bottom curve for comparison. The inset is $\mathrm{D}_{2} \mathrm{O}$ TPD area as a function of $\mathrm{O}_{2}$ exposure.

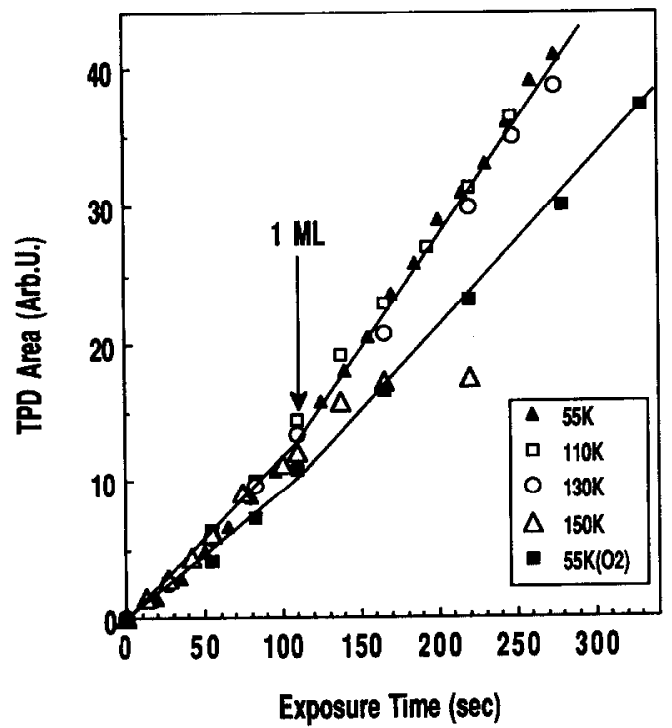

Fig. 5. $\mathrm{D}_{2} \mathrm{O}$ uptake, determined by TPD areas, on $\mathrm{Pt}(111)$ and $\mathrm{O}_{2}$-precovered (filled squares; dosed at $55 \mathrm{~K}$ ) $\mathrm{Pt}(111)$ for various adsorption temperatures. and no measureable desorption of $\mathrm{H}_{2}$ above background levels.

Turning to molecular oxygen, fig. 5 , the significantly lower uptake rate, compared with the clean surface, is likely an artifact due to disproportionation of surface OD to give, in addition to $\mathrm{D}_{2} \mathrm{O}$, some and $\mathrm{O}_{2}$ and $\mathrm{D}_{2}$ desorption $[2,26]$, i.e., the TPD area underestimates the uptake. Interestingly, the slope for the $\mathrm{O}_{2}$-precovered surface also changes at $1 \mathrm{ML} \mathrm{D}_{2} \mathrm{O}$ coverage.

\subsection{TPD of $\mathrm{C}_{2} \mathrm{H}_{5} \mathrm{Cl}$ on clean and $\mathrm{D}_{2} \mathrm{O}$-precovered $P t(111)$}

Turning to $\mathrm{C}_{2} \mathrm{H}_{5} \mathrm{Cl}$, fig. 6 shows TPD spectra after adsorption on $\mathrm{Pt}(111)$ for various exposures. $\mathrm{C}_{2} \mathrm{H}_{5} \mathrm{Cl}$ adsorbs and desorbs associatively (molecularly) on Pt(111) [18,19]. Three desorption peaks, 115, 119 and $172 \mathrm{~K}$, were observed. The right panel is an expansion of the spectra in the 90-140 


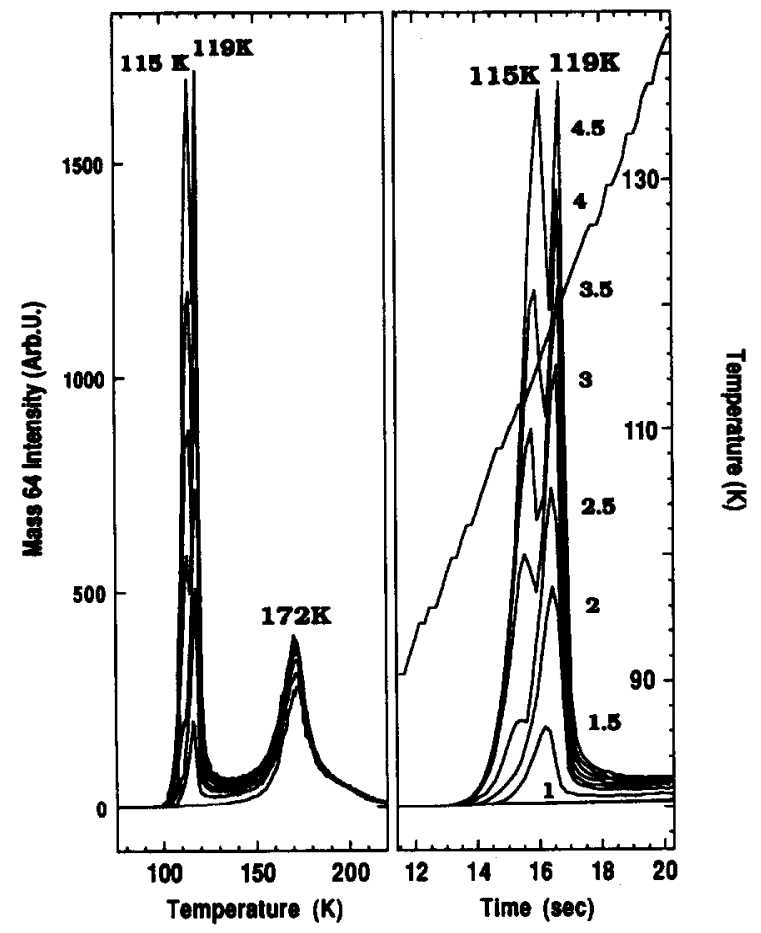

Fig. 6. TPD spectra of $\mathrm{C}_{2} \mathrm{H}_{5} \mathrm{Cl}$ adsorbed at $60 \mathrm{~K}$ on $\mathrm{Pt}(111)$. Right panel is an expanded version of the left panel for the 90-140 $\mathrm{K}$ range (also shown is the temperature versus time plot). The total coverages are indicated on each curve in right panel. The ramp rate was $5.875 \mathrm{~K} / \mathrm{s}$.

$\mathrm{K}$ range to better show the growth of the two narrowly positioned peaks. The spectra are plotted as a function of time to eliminate the $x$-axis electrical noise (which can be seen in the left panel) picked up during the temperature read-in. The temperature versus time plot (diagonal line) demonstrates the linearity of our temperature ramp $(5.875 \pm 0.001 \mathrm{~K} / \mathrm{s}$ in the range of interest). The $115 \mathrm{~K}$ peaks shifted to higher temperatures (longer times), shared leading edges, and did not saturate with increasing exposure, all characteristic of zero-order desorption from a condensed state. In contrast, the $119 \mathrm{~K}$ peak grew in before the $115 \mathrm{~K}$ peak, did not share leading edges, and saturated with increasing exposure. The apparent increase of the $119 \mathrm{~K}$ peak intensity with increasing exposure is due to its overlap with $115 \mathrm{~K}$ peak. In addition, the overall width of the 115 and $119 \mathrm{~K}$ peaks is too large to be accounted for by a single physisorption interaction, e.g. the width is comparable to that of the $172 \mathrm{~K}$ (chemisorption) peak. We, therefore, conclude that the peaks at 119 and 115 $\mathrm{K}$ represent desorption from the second and higher layers of $\mathrm{C}_{2} \mathrm{H}_{5} \mathrm{Cl}$, respectively.

Fig. 7 shows $\mathrm{C}_{2} \mathrm{H}_{5} \mathrm{Cl}$ TPD spectra for a fixed exposure (50s dose $\cong 1 \mathrm{ML})$ and various $(0-6$ $M E$ ) precoverages of $\mathrm{D}_{2} \mathrm{O}$. Interestingly, a number of new desorption features are observed. For small $\mathrm{D}_{2} \mathrm{O}$-precoverages, two peaks ( $\alpha$ and $\beta$ ) grow in with comparable intensities, accompanied by simultaneous decrease of the clean surface $\mathrm{C}_{2} \mathrm{H}_{5} \mathrm{Cl}$ desorption (172 K). Peak $\alpha$ initially increases, and then decreases above $1 \mathrm{ML}$ of $\mathrm{D}_{2} \mathrm{O}$ precoverage, while peak $\beta$ increases monotonically with increasing water coverage. This result is discussed in terms of the water bilayer structure in the following section. Also shown, as an inset, is the integrated $\mathrm{C}_{2} \mathrm{H}_{5} \mathrm{Cl}$ TPD area for a fixed exposure (50 s dose) as a function of $\mathrm{D}_{2} \mathrm{O}$-precoverage; the

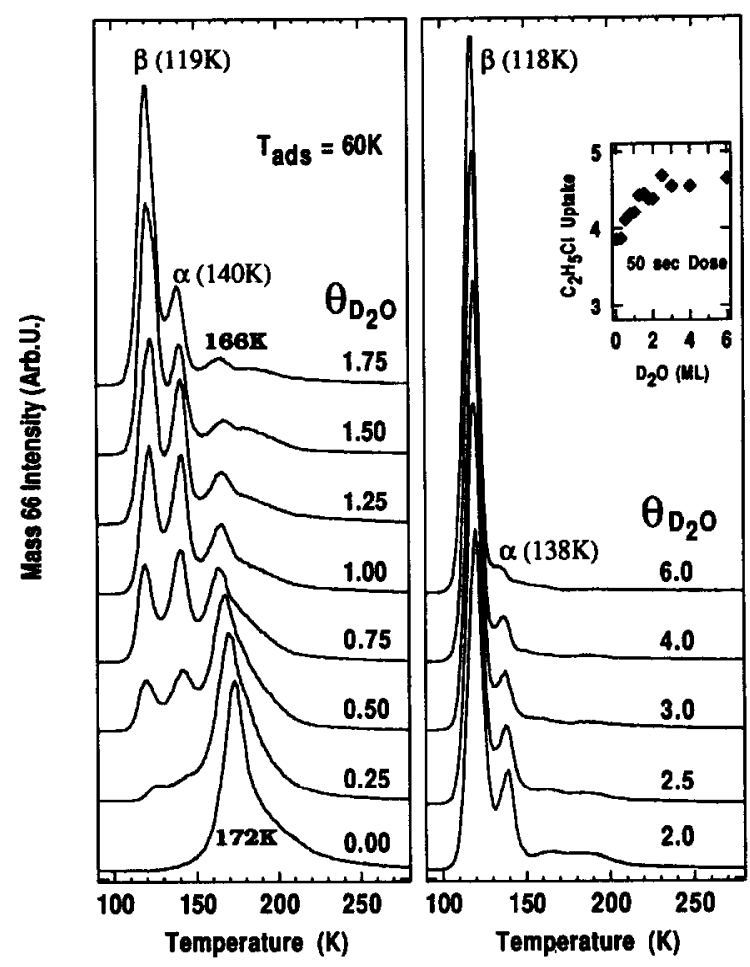

Fig. 7. TPD spectra of $\mathrm{C}_{2} \mathrm{H}_{5} \mathrm{Cl}$ with a $50 \mathrm{~s}$ dose $(\sim 1 \mathrm{ML})$ on $\mathrm{D}_{2} \mathrm{O}$-precovered $\mathrm{Pt}(111)$ for various coverages (indicated in the figure) of $\mathrm{D}_{2} \mathrm{O}$. Adsorption temperature was $60 \mathrm{~K}$ for both $\mathrm{D}_{2} \mathrm{O}$ and $\mathrm{C}_{2} \mathrm{H}_{5} \mathrm{Cl}$. The inset shows the $\mathrm{C}_{2} \mathrm{H}_{5} \mathrm{Cl}$ uptake versus $\mathrm{D}_{2} \mathrm{O}$ coverage. 


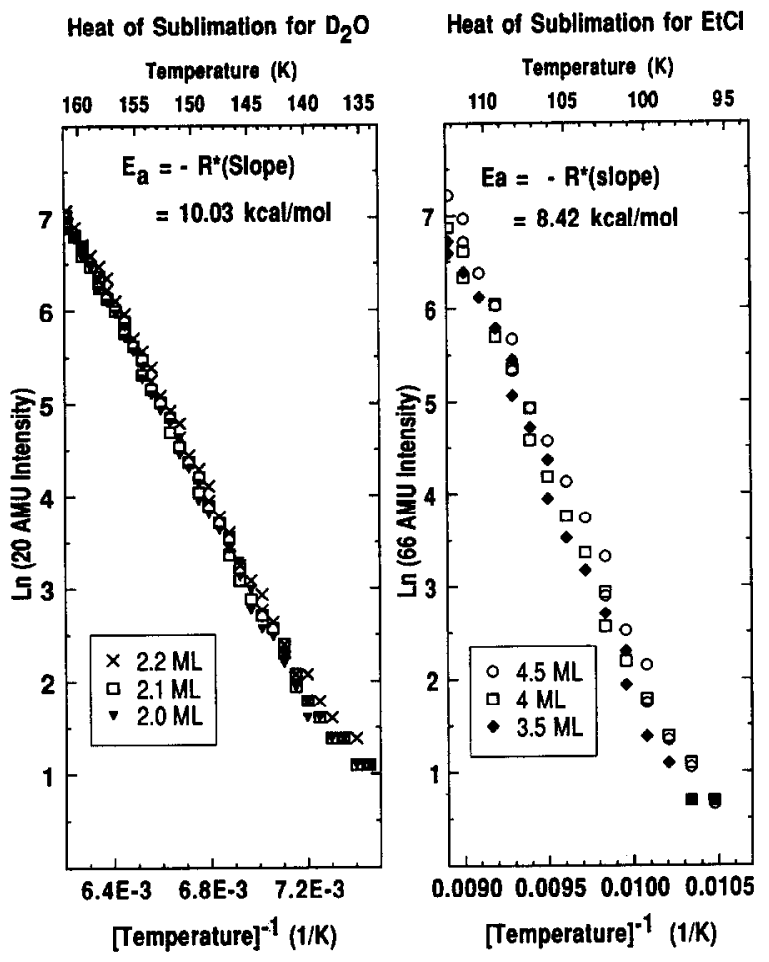

Fig. 8. Plot of the logarithm of the desorption signals versus reciprocal surface temperature for $\mathrm{D}_{2} \mathrm{O}$ (fig. 1) and $\mathrm{C}_{2} \mathrm{H}_{5} \mathrm{Cl}$ (fig. 6). Activation energies for desorption, i.e., heats of sublimation, which are obtained from the slopes, are also shown.

sticking probability of $\mathrm{C}_{2} \mathrm{H}_{5} \mathrm{Cl}$ on an ice-covered surface is higher than on clean $\operatorname{Pt}(111)$ and contrasts with the $\mathrm{D}_{2} \mathrm{O}$ adsorption on a $\mathrm{D}$-precovered surface (see the inset of fig. 4).

Fig. 8 shows semi-logarithmic plots of the desorption signal intensities versus reciprocal temperature, the slopes of which give activation energies for desorption, i.e., heats of sublimation, for $\mathrm{D}_{2} \mathrm{O}$ and $\mathrm{C}_{2} \mathrm{H}_{5} \mathrm{Cl}$. Comparison with literature values provides a measure of the quality of the spectra obtained in this work.

\section{Discussion}

\section{1. $\mathrm{D}_{2} \mathrm{O}$ TPD on $\mathrm{Pt}(111)$}

With few exceptions [2,6], water molecules form hydrogen-bonded islands at very low coverages because the energy associated with hydrogen bonding is comparable with or greater than the water-surface interaction. Fisher and Gland [3] observed that, with increasing exposure, a TPD peak at $170 \mathrm{~K}$ grew in at very low coverages as a shoulder to another peak at $180 \mathrm{~K}$. For higher doses, but less than one monolayer, their TPD was dominated by one peak that shifted to higher temperatures with dose. This led them to conclude near-zero order kinetics for the monolayer desorption, which is rarely the case for chemisorbed molecules on metal surfaces. They attributed this unusual observation to desorption from hydrogenbonded water islands.

Our comparable TPD spectra (figs. 1 and 3), however, show no peak shift for either the $171 \mathrm{~K}$ $\left(A_{1}\right)$ or $178 \mathrm{~K}\left(\mathrm{~A}_{2}\right)$ peak. because of changing relative intensities, an unresolved composite of the two would shift to higher temperatures and would have about the width observed by Fisher and Gland [3]. We suggest that our results differ from earlier work only in that our dosing and uniform sample heating give us a better resolution and, thereby, a somewhat more refined interpretation of the desorption kinetics.

We find on $\mathrm{Pt}(111)$, less than $10 \mathrm{~K}$ separation between $A_{1}$ and $A_{2}$, and that multilayer desorption does not appear until $A_{1}$ and $A_{2}$ are more than $80 \%$ saturated (fig. 1). On Ru(001), Doering et al. [7] observed multilayer desorption beginning at $\sim 10 \%$ of the saturation of the chemisorbed layer, and attributed this to cluster formation in which multilayer ice patches grow long before the surface is covered. This is very interesting difference between $\operatorname{Ru}(001)$ and $\operatorname{Pt}(111)$, particularly considering the stability of chemisorbed, compared to physisorbed, water on $\operatorname{Ru}(001)(\sim 30 \mathrm{~K}$ peak separation).

Since the two peaks, $A_{1}$ and $A_{2}$, do not shift with coverage, they are interpretable in terms of simple first-order desorption kinetics. As for earlier work [3], we suppose that bilayer islands form at low coverages, that desorption of molecules from the upper half of the bilayer requires slightly less energy than from the lower half, and that rearrangement and desorption of these islands leads to two TPD peaks $\left(A_{1}\right.$ and $\left.A_{2}\right)$. The structure at the perimeter of these islands is important [2] and is discussed below. The larger relative $A_{2}$ intensity for higher adsorption temperatures, suggests that 
there is a kinetic barrier between $A_{1}$ and $A_{2}$; a barrier that makes desorption and conversion competitive on the TPD time scale. For higher adsorption temperatures, the greater thermal energy during adsorption would promote more rapid and extensive long-range $\mathrm{H}$-bonded bilayer ordering, and could account for the increased relative $A_{2}$ intensity (fig. 2).

Considering the strong tendency for intermolecular hydrogen bonding, partial loss of molecules from the upper half of the bilayer would likely lead to extensive rearrangement that would restore the bilayer structure in islands. This could involve breaking up old islands. Thus, we do not expect the peak areas of $A_{1}$ and $A_{2}$ desorption to reflect quantitatively the stoichiometries present at the start of the TPD cycle.

We turn now to small clusters and to edges, which will be particularly important in small islands. In related work on $\mathrm{Ru}(001)$, Doering and Madey [7] proposed small bilayer clusters for submonolayer coverages, containing "flop-down" molecules (molecules in the upper half of the hexagonal unit for which both, rather than one, $\mathrm{H}$ atoms are $\mathrm{H}$-bonded to the underlying molecules). The desorption energy of these is the same as the molecules in the lower half.

These ideas can qualitatively account for the low coverage observations we have made on Pt(111) and must be taken into account at any coverage when describing the intensity in the $A_{1}$ peak. For example, the negligible intensity of $\mathbf{A}_{2}$ at very low coverages in fig. 1 may indicate either isolated water molecules, as reported recently for $\mathrm{H}_{2} \mathrm{O}$ adsorbed on $\mathrm{Pt}(111)$ at $20 \mathrm{~K}$ [6], or, more likely, the existence of water molecules in small bilayer cluster units [2,7] in which "flop-down" molecules contribute to the $A_{1}$ intensity. More convincing evidence of the low coverage structure as a function of adsorption temperature, however, awaits other spectroscopic measurements (e.g., ESDIAD and LEED).

\section{2. $\mathrm{C}_{2} \mathrm{H}_{5} \mathrm{Cl} T P D$ on clean and $\mathrm{D}_{2} \mathrm{O}$-precovered Pt(III)}

Lloyd et al. [19] have recently studied $\mathrm{C}_{2} \mathrm{H}_{5} \mathrm{Cl}$ TPD on $\mathrm{Pt}(111)$. Although their peak tempera- tures (115 and $170 \mathrm{~K}$ ) agree reasonably well with those in fig. 6, they do not show high-coverage ( $>1.2 \mathrm{ME}$ ) spectra, because multilayers are unstable at their dosing temperature $(100 \mathrm{~K})$. All our experimental evidence, however, clearly suggests TPD distinction of the first and the second layers from each other and from thicker layers of $\mathrm{C}_{2} \mathrm{H}_{5} \mathrm{Cl}$. The highly-oriented ( $\mathrm{Cl}$-end down) geometry of the first layer, evidenced by the large negative work function change $(\Delta \phi=-1.2 \mathrm{eV}$ with $1 \mathrm{ML} \mathrm{C}_{2} \mathrm{H}_{5} \mathrm{Cl}$ ) and by HREELS results [19], is likely to partially orient the second layer and in the same direction. In this layer-by-layer stacking model, the net charge transfer from the first layer to the surface will induce slightly stronger second-layer adsorption on the monolayer-covered surface compared to the adsorption on thicklycovered ( $\geq 2 \mathrm{ML}$ ) surfaces, and could result in the $4 \mathrm{~K}$ separation of the second layer from higher ( $\geq 3 \mathrm{ML}$ ) layers in TPD.

According to this model, multilayer peak splitting, as observed here, is likely for polar adsorbates whenever a large temperature gap between the first and higher layer desorption (50 K for $\mathrm{C}_{2} \mathrm{H}_{5} \mathrm{Cl}$ ) is observed. It is noteworthy that, on $\mathrm{Ag}(111), \mathrm{a}-2 \mathrm{~K}$ separation of second layer from multilayer $\mathrm{Xe}$, a nonpolar species with a rather large induced-dipole, was observed [20]. This result, at first surprising, is an independent demonstration that resolution of second adsorbed layers can be realized under certain conditions.

$\mathrm{C}_{2} \mathrm{H}_{5} \mathrm{Cl}$ TPD on water-precovered $\mathrm{Pt}(111)$ (fig. 7) shows that we can probe the relative surface concentration of sites of different adsorption strengths created by the coverage-dependent structure of $\mathrm{D}_{2} \mathrm{O}$ on $\mathrm{Pt}(111)$. If we associate peak $\beta$ to $\mathrm{C}_{2} \mathrm{H}_{5} \mathrm{Cl}$ desorption from regions where the water bilayer is fully developed and peak $\alpha$ to regions where it is not, including the perimeter of islands, all the above-mentioned features are amenable to an easy explanation in terms of desorption temperatures, growth features, and relative concentrations of the two different adsorption sites. This may well be an oversimplification in that peak $\beta$ occurs in the same region as the second and multi-layer peaks for $\mathrm{C}_{2} \mathrm{H}_{5} \mathrm{Cl}$ alone. However, the data of fig. 7 were taken with a fixed monolayer dose of ethyl chloride and we believe it is highly 
unlikely that the $119 \mathrm{~K}$ peak is attributable to desorption of $\mathrm{C}_{2} \mathrm{H}_{5} \mathrm{Cl}$ from $\mathrm{C}_{2} \mathrm{H}_{5} \mathrm{Cl}$ multilayer. For example, consider the $1 \mathrm{ML} \mathrm{C}_{2} \mathrm{H}_{5} \mathrm{Cl}-1 \mathrm{ML}$ $\mathrm{D}_{2} \mathrm{O}$ case of fig. 7. The $\alpha$ and $\beta$ desorption peaks have about equal intensity and we find no compelling reason to attribute the lowest temperature peak to multilayer (or second layer) ethyl chloride desorption. Rather, we take this distribution to indicate that the bilayer islands of water, formed by adsorption at $60 \mathrm{~K}$, are small leaving many edge sites where $\beta-\mathrm{C}_{2} \mathrm{H}_{5} \mathrm{Cl}$ forms. Further work is clearly needed to explore and exploit this site sensitivity.

For high precoverages of $\mathrm{D}_{2} \mathrm{O}(>2 \mathrm{ME}$ ), the major ethyl chloride desorption is at $118 \mathrm{~K}$, with slightly larger width than either peak $\alpha$ or $\beta$ in the low precoverage regime. We suppose, for high coverages $(>2 \mathrm{ML})$, that the distinction is lost between the two kinds of bilayer sites. The relative peak area of the 166-172 $\mathrm{K} \mathrm{C}_{2} \mathrm{H}_{5} \mathrm{Cl}$ desorption reflects the fraction of the surface where there are no water molecules. Above $1 \mathrm{ML} \mathrm{D}_{2} \mathrm{O}$-precoverage, this clean surface desorption $(\sim 30 \%$ of the total at $\sim 1 \mathrm{ML}$ ) retains its intensity to as high as $3 \mathrm{ML} \mathrm{D}_{2} \mathrm{O}$-precoverage. This is attributed mainly to $\mathrm{C}_{2} \mathrm{H}_{5} \mathrm{Cl}$ adsorption on those bare $\mathrm{Pt}$ atoms $\left(\frac{1}{3}\right.$ of the total surface $\mathrm{Pt}$ atoms at $1 \mathrm{ML} \mathrm{D}_{2} \mathrm{O}$-coverage) remaining exposed at the center of hexagonal units comprising the water bilayer (see scheme 1) $[2,8]$, and partly to the imperfect layer-by-layer growth of the water layers. That the peak areas of $\alpha$ and $\beta$ are about the same and are each $\frac{1}{3}$ of the total desorption at $1 \mathrm{ML} \mathrm{D}_{2} \mathrm{O}$-precoverage is also consistent with the above assignments.

\section{3. $\mathrm{D}_{2} \mathrm{O}$ TPD on $\mathrm{O}_{2}, \mathrm{O}$-, and D-precovered $\mathrm{Pt}(111)$}

We now turn to the effects of modified surfaces on $\mathrm{D}_{2} \mathrm{O}$ TPD. Since many detailed studies on these systems have already been published $[2,3,9,15,21-25]$, we focus only on the effect of surface additives on the first layer desorption features ( $A_{1}$ and $A_{2}$ in fig. 1). Briefly, $O_{2}$ adsorbs molecularly at $\leq 100 \mathrm{~K}$ on $\mathrm{Pt}(111)$, and partly desorbs and partly decomposes into surface atoms at $150 \mathrm{~K}$. On O-precovered $\mathrm{Pt}(111)$, water adsorbs molecularly, and, upon subsequent heating, decomposes into surface hydroxyls (150-200 K range), which desorb as water by recombination at $\sim 200 \mathrm{~K}[21,22]$.

As seen in fig. 3, the molecular and atomic oxygen-precovered surfaces give $\mathrm{D}_{2} \mathrm{O}$ TPD features that differ only slightly. The high temperature peaks (203-204 K) are in good agreement with other work $[3,21,22]$, and are attributed to OP disproportionation [2]. The $163 \mathrm{~K}$ peak on the $\mathrm{O}_{2}$-covered surface shows characteristic zero-order desorption (i.e., multilayer desorption) while on the $\mathrm{O}$-covered surface it grows in as a shoulder to the $167 \mathrm{~K}$ peak, and then becomes dominant. The $167 \mathrm{~K}$ peak on the $\mathrm{O}$-covered $\mathrm{Pt}(111)$ is attributed to $\mathrm{D}_{2} \mathrm{O}$ desorption from the OD-covered surface. It occurs at a higher temperature than multilayer desorption and does not follow zero-order kinetics. Mitchell et al. [22] also observed $\mathrm{H}_{2} \mathrm{O}$ TPD spectra on O-covered $\mathrm{Pt}(111)$ with a slight peaksplitting at $\sim 165 \mathrm{~K}$. We note that the $167 \mathrm{~K}$ peak on the O-precovered surface occurs at about the same temperature as the $A_{2}$ peak of fig. 1 . This is reasonable, since binding of water molecules on surface $\mathrm{OH}$ and/or $\mathrm{O}$ atoms should be similar to that of molecules in the upper half of the water bilayer. On the $\mathrm{O}_{2}$-covered surface, however, the $167 \mathrm{~K}$ peak is not observed, probably because of the nearly concomitant desorption and dissociation of $\mathrm{O}_{2}$ and $\mathrm{D}_{2} \mathrm{O}$. Most likely, an ordering (orientation) requirement for $\mathrm{H}$-bonding which is not met by water molecules in the presence of surface oxygen, accounts for the absence of desorption characteristic of the bilayer structure $[25,26]$.

To the best of our knowledge, $\mathrm{D}_{2} \mathrm{O}$ TPD on hydrogen-covered $\mathrm{Pt}(111)$ has not been reported. On Ni(100), down-shifted peak temperatures of monolayer $\mathrm{D}_{2} \mathrm{O}$ desorption and the inhibition of $\mathrm{D}_{2} \mathrm{O}$ decomposition with increasing $\mathrm{D}$-precoverage were reported [26]. D-precoverage on $\mathrm{Pt}(111)$ has a similar effect on $\mathrm{D}_{2} \mathrm{O}$ TPD, as shown in fig. 4. Surface hydrogen inhibits the bilayer formation and weakens the water-Pt interaction. From the suppression of the $171 \mathrm{~K}$ peak $\left(\mathrm{A}_{2}\right)$ by very low D-precoverages ( $\sim 5 \%$ of saturation), it is clear that small amounts of background hydrogen adsorption prevent the double-peaked desorption for the first layer of water on $\mathrm{Pt}(111)$. The most likely adsorption geometry of $\mathrm{D}_{2} \mathrm{O}$ on the D-covered 
surface is with the oxygen down and hydrogenbonded to the two nearest surface $D$ atoms at three-fold hollow sites. This suggested structure is consistent with: (1) the lack of split desorption peaks (absence of bilayer structure); (2) the down-shifted (to $\sim 170 \mathrm{~K}$ ) desorption temperature (due to increased lateral repulsion) within the first $\mathrm{D}_{2} \mathrm{O}$ layer; and (3) the fact that the desorption of chemisorbed $\mathrm{D}_{2} \mathrm{O}$ from D-saturated $\mathrm{Pt}(111)$ maximizes at $\mathrm{D}_{2} \mathrm{O} / \mathrm{Pt} \cong 0.5$ estimated by comparing the areas of the $A_{2}(171 \mathrm{~K})$ peak and the saturation first layer peak on $\sim \mathrm{D}$-saturated $\operatorname{Pt}(111)$.

\subsection{Sticking coefficients, desorption kinetics, and activation energies}

The results of fig. 5 indicate, contrary to some published data $[2,27]$, that the $\mathrm{H}_{2} \mathrm{O}$ adsorption probability on $\mathrm{Pt}(111)$ is coverage-dependent. Surface decomposition, a possible cause for an apparently low uptake, can be sensitively detected by the high temperature $(>200 \mathrm{~K})$ peak in TPD (see fig. 3 and ref. [3]); the absence of this peak (see fig. 3) rules out this possible contribution. The temperature-independent sticking coefficient, which is in accord with other results [2], suggests that the lower sticking coefficient in the lowcoverage regime is not determined by barriers to diffusion and rearrangement after adsorption, but probably by the dynamics of the incoming molecules [28]. The lower TPD peak areas on the $\mathrm{O}_{2}$-precovered surface compared with the clean surface is attributed in part to the incomplete recovery (into $\mathrm{D}_{2} \mathrm{O}$ ) of the decomposed water molecules due to the disproportionation of $O D$ into $\mathrm{D}_{2}$ and $\mathrm{O}_{2}$ desorptions during TPD [15].

It is interesting that the sticking probability of $\mathrm{D}_{2} \mathrm{O}$ decreases with $\mathrm{D}$-precoverage (fig. 4), while those of $\mathrm{D}_{2} \mathrm{O}$ (fig. 5) and $\mathrm{C}_{2} \mathrm{H}_{5} \mathrm{Cl}$ (fig. 7) increase with $\mathrm{D}_{2} \mathrm{O}$-precoverage. This difference is probably a result of different bonding requirements (e.g., azimuthal ordering), different local electric field effects induced by underlying species [29], and/or different dynamical factors. Along these lines, the $\mathrm{C}_{2} \mathrm{H}_{5} \mathrm{Cl}$ results can be rationalized as follows. While two $\mathrm{C}_{2} \mathrm{H}_{5} \mathrm{Cl}$ bonding sites of different adsorption strengths (two TPD peaks, $\alpha$ and $\beta$ ) are present for $<2 \mathrm{ML} \quad \mathrm{D}_{2} \mathrm{O}$-precoverages, only a single site (the single peak, $\beta$ ) is present for high ( $>3 \mathrm{ML}$ ) $\mathrm{D}_{2} \mathrm{O}$-precoverages. The latter is attributable to an amorphous $\mathrm{D}_{2} \mathrm{O}$ structure. Thus, as observed, $\mathrm{C}_{2} \mathrm{H}_{5} \mathrm{Cl}$ adsorption would be less probable for low ( $<2 \mathrm{ML}$ ) water precoverages due to its site specific nature (upper and lower halves of the bilayer). This subject deserves more theoretical and experimental investigation.

The heat of sublimation for water should be comparable to the energy $(8-12 \mathrm{kcal} / \mathrm{mol}) \mathrm{re}-$ quired to break two $\mathrm{H}$-bonds. The value obtained from the kinetic analysis of the zero-order desorption signal, $10.3 \mathrm{kcal} / \mathrm{mol} \mathrm{(fig.} \mathrm{8),} \mathrm{is} \mathrm{in} \mathrm{good}$ agreement with thermodynamic literature (9.9 $\mathrm{kcal} / \mathrm{mol}$ ) $[2,30]$ and with previous thermal desorption work $[3,7,14]$. For $\mathrm{C}_{2} \mathrm{H}_{5} \mathrm{Cl}$, the value of $8.42 \mathrm{kcal} / \mathrm{mol}$ from fig. 8 is somewhat higher than the reported heat of sublimation $(6.3 \mathrm{kcal} / \mathrm{mol})$ [31].

\section{Conclusions}

Our results can be summarized as follows:

(1) Associatively adsorbed water on $\mathrm{Pt}(111)$ desorbs with three distinct peaks - 160-167 K, 170-171 K, and 177-178 K - ascribed to desorption of multilayer ice, to bilayer regions, and to non-bilayer regions, respectively.

(2) Water TPD spectra on oxygen- and deuterium-precovered $\operatorname{Pt}(111)$ further support this bilayer attribution.

(3) The sticking probability of water was independent of adsorption temperature for the 55-150 $K$ range, but was lower $(\leq 0.7)$ in the first bilayer than in the multilayer regime.

(4) $\mathrm{C}_{2} \mathrm{H}_{5} \mathrm{Cl}$, molecularly adsorbed on $\mathrm{Pt}(111)$, also desorbs with three peaks at $112-115 \mathrm{~K}, 118-$ $119 \mathrm{~K}$, and $172-173 \mathrm{~K}$. These are attributed to desorption of condensed multilayers, the second layer and the first layer of $\mathrm{C}_{2} \mathrm{H}_{5} \mathrm{Cl}$, respectively.

(5) TPD of $\mathrm{C}_{2} \mathrm{H}_{5} \mathrm{Cl}$ on $\mathrm{D}_{2} \mathrm{O}$-precovered $\mathrm{Pt}(111)$ was a sensitive probe for the slightly different adsorption environments provided by various structures of water.

(6) Heats of sublimation for $\mathrm{D}_{2} \mathrm{O}(10.3 \mathrm{kcal} /$ mol) and $\mathrm{C}_{2} \mathrm{H}_{5} \mathrm{Cl}(8.42 \mathrm{kcal} / \mathrm{mol})$ were calculated. 


\section{Acknowledgement}

This work supported by the National Science Foundation, Grant CHE9015600.

\section{References}

[1] D. Graf, M. Grundner, D. Ludecke and R. Schulz, J. Vac. Sci. Technol. A 8 (1990) 1955.

[2] P.A. Thiel and T.E. Madey, Surf. Sci. Rep. 7 (1987) 211, and references therein.

[3] G.B. Fisher and J.L. Gland, Surf. Sci. 94 (1980) 446.

[4] H. Ibach and S. Lehwald, Surf. Sci. 91 (1980) 187.

[5] E. Langenbach, A. Spitzer and H. Luth, Surf. Sci. 147 (1984) 179.

[6] W. Ranke, Surf. Sci. 209 (1989) 57.

[7] D. Doering and T.E. Madey, Surf. Sci. 123 (1982) 305.

[8] R.N. Barnett, U. Landman and A. Nitzan, private communications.

[9] C. Benndorf and T.E. Madey, Surf. Sci. 194 (1988) 63.

[10] B.W. Callen, K. Griffiths, U. Memmert, D.A. Harrington, S.J. Bushby and P.R. Norton, Surf. Sci. 230 (1990) 159.

[11] M.R. Columbia and P.A. Thiel, Surf. Sci. 235 (1990) 53.

[12] F.T. Wagner and T.E. Moylan, Surf. Sci. 206 (1988) 187.

[13] M.J. Bozak, L. Meuhlhoff, J.N. Russell, W.J. Choyke and J.T. Yates, Jr, J. Vac. Sci. Technol. A 5 (1987) 1.

[14] P.J. Schmitz, J.A. Polta, S.-L. Chang and P.A. Thiel, Surf. Sci. 186 (1987) 219.
[15] J.R. Creighton and J.M. White, Surf. Sci. 136 (1984) 449.

[16] K. Jacobi and H.H. Rotermund, Surf. Sci. 133 (1983) 401.

[17] P.A. Thiel, F.M. Hoffmann and W.H. Weinberg, J. Chem. Phys. 75 (1981) 5556.

[18] S.K. Jo and J.M. White, Surf. Sci. 245 (1991) 305.

[19] K.G. Lloyd, B. Roop, A. Campion and J.M. White, Surf. Sci. 214 (1989) 227.

[20] R.J. Behm, C.R. Brundle and K. Wandelt, J. Chem. Phys. 85 (1986) 1061

[21] G.B. Fisher and B.A. Sexton, Phys. Rev. Lett. 44 (1980) 683.

[22] G.A. Mitchell, S. Akhter and J.M. White, Surf. Sci. 166 (1986) 283.

[23] K.M. Ogle and J.M. White, Surf. Sci. 139 (1984) 43.

[24] M. Kiskinova, G. Pirug and H.P. Bonzel, Surf. Sci. 150 (1985) 319.

[25] T.E. Madey and F.P. Netzer, Surf. Sci. 117 (1982) 549.

[26] D.E. Peebles and J.M. White, Surf. Sci. 144 (1984) 512.

[27] G.B. Fisher, Monolayer and Multilayer Adsorption of Water on the Pt(111) Surface, General Motors Research Publication No. GMR-4007/PCP-171 (1982).

[28] E.W. Kuipers, M.G. Tenner, A.W. Kleyn and S. Stolte, J. Vac. Sci. Technol. A 8 (1990) 2692.

[29] P.A. Dowben, CRC Crit. Rev. Solid State Mater. Sci. 13 (1987) 191.

[30] The Merck Index: An Encyclopedia of Chemicals and Drugs, 10th ed. (Merck Co., Inc., 1983).

[31] CRC Handbook of Chemistry and Physics, 68th ed. (CRC Press, Boca Raton, 1987). 